\title{
What can population-based physician billing data tell us about the prevalence, costs and disorders associated with different types of cancers based on the 16 years prevalence of cancer diagnosis?
}

\author{
Jazmin Lui ${ }^{1}$, Aru Narendran ${ }^{2}$, David Cawthorpe ${ }^{3}$ \\ 1. Queen's Univeristy, Faculty of Science, Canada. 2. University of Calgary, Department of Oncology, Canada. \\ 3. University of Calgary, Departments of Psychiatry and Community Health Sciences, Canada.
}

Correspondence: David Cawthorpe. Address: University of Calgary, Dept. of Psychiatry \& Community Health Science, Richmond Road Diagnostic and Treatment Center, 2nd Floor, RM 2603, 1820 Richmond Road S.W., Calgary, Alberta, Canada T2N 1N4. E-mail: cawthord@ucalgary.ca

Received: May 2, 2013

DOI : $10.5430 /$ jha.v3n4p9
Accepted: October 9, 2013

Online Published: January 23, 2014

\section{Abstract}

Background: Annual rates of cancer diagnosis and costs are reported for specific cancers and age groups over 16 years using health utilization data in addition to the odds ratios for broad International Classification of Disease (ICD) categories of associated disorders.

Methods: Using physician assigned ICD diagnosis, annual cancer diagnosis rates of six cancers (colorectal, breast, prostate, lung, mesothelioma, and pancreatic) were measured for the period of 1994-2009 in the Calgary, Alberta catchment area. As well, the patient cohort diagnosed with any neoplasm $(n=261,896)$ was analyzed by year for three age groups: youth ( $<25$ years), adult (26 years -69 years), and geriatric ( $\geq 70$ years). Total direct cancer diagnosis costs and associated disorders costs were calculated by year and mean total costs compared by type of cancer. Odds ratio were calculated for each broad category of ICD diagnosis given the presence or absence of specified cancer types.

Results: Annual rates of diagnosis increased for all six cancers and all three age groups. All six cancers showed their annual rates of diagnosis to be at least 2.1 times greater in 2009 compared to 1994. Colorectal cancer maintained the highest annual cancer rate of diagnosis, the geriatric group had the highest annual rates of cancer diagnosis out of the three age groups, and the youth group annual rates of cancer diagnosis increased by a factor of 2.6. Breast cancer had the highest associated per patient costs whereas prostate cancer had the lowest. In addition to other neoplasms, odds ratios indicated that most cancer types were associated with disorders of the blood and blood producing organs.

Conclusion: Prevalence has been steadily increasing in the Calgary, AB catchment over the study period. Trends in annual rates of diagnosis have implications for future burden on healthcare systems and provide a basis for comparison of local rates and expenditures with other healthcare principalities.

\section{Key words}

Cancer rates, Population study, Physician diagnosis, International classification of disease 


\section{I ntroduction}

The investigation of trends in cancer prevalence, incidence, and mortality is of growing concern to the public as cancer has been ranked number one among ten leading causes of death in Canadians since 2000; in 2008 cancer was reported to have caused $29.6 \%$ of deaths in Canada ${ }^{[1]}$. In this paper we consider six types of both common and uncommon cancers (see Table 1): 3 with poor and 3 with better survival rates. For example, Table 1 describes the percentage total new cases and the relative survival rates for each type of cancer: Breast, Prostate, Colorectal, Lung, Pancreatic, and Mesothelioma.

The four common cancers in Canada are prostate, breast, lung, and colorectal ${ }^{[2]}$. Breast and prostate cancer are the most common cancer types in women and men, respectively. Colorectal cancer is the third most common cancer among both women and men, with significantly declining incidence in both sexes since $2000{ }^{[2]}$.

While breast, prostate, and colorectal cancer have relatively high survival rates, the other end of the spectrum is represented by lung, pancreatic, and mesothelioma cancer. Lung cancer holds the highest mortality rates in both men and women and accounts for $27 \%$ of cancer deaths in Canada ${ }^{[2]}$. Pancreatic cancer has low survival rates ${ }^{[2,5-7]}$. Mesothelioma incidence rates have been increasing ${ }^{[8]}$ and are amongst the most fatal cancers ${ }^{[5,9]}$.

Table 1. Types of cancer, incidence and survival (39)

\begin{tabular}{lllll}
\hline Type & New Cases & Incidence per 100,000 & Observed 5 year survival & Survival \\
\hline Breast & $26 \%$ & 138 & $80 \%$ & Improved \\
Prostate & $25 \%$ & 121 & $81 \%$ & Improved \\
Colorectal & $14 \%$ & 62 & $54 \%$ & Improved \\
Lung & $14 \%$ & 68 & $12 \%$ & Poor \\
Pancreatic & $2.5 \%$ & 12 & $8 \%$ & Poor \\
Mesothelioma & $0.6 \%$ & 1.2 & $7 \%$ & Poor \\
\hline
\end{tabular}

Health utilization data may be used to understand long-term trends in cancer rates of diagnosis. In this study we describe a range of cancers in terms of direct costs, costs of associated disorders, age dependence and annual prevalence rates based on a physician billing data from a representative sample from a regional population.

\section{Methods}

Data source: Canada provides universal coverage for medically necessary health services. Services include physician visits that are covered by provincial health plans. All Alberta Physicians directly bill the provincial health plan for each patient visit in order to receive payment for the treatment delivered. Each billing includes at minimum a unique patient identifier, an International Classification of Diseases (ICD) diagnosis, and a visit cost, which is submitted and registered as a unique patient visit with Alberta Health and Wellness. Physician billing data (Calgary Research Ethics Board ID 21695) for patients from the Calgary Zone in Alberta was collected for the period of 1994-2009. A physician billing dataset was compiled consisting of records of all health services rendered to a representative population sample of individuals from the Calgary Zone who sought health care for a specified problem on a specified date and subsequently were assigned an ICD diagnosis (all diagnoses were counted).

Physician billing data is distinct from the Canadian Cancer registry. The Canadian Cancer registry is more comprehensive in terms of calculating specific incidence and mortality. In this study we represent annual presentation of physician diagnoses of specified cancers. We report the annual rates of International Classification of Disease physician-assigned diagnosis in a population sample from the Calgary, Alberta catchment $(n=764,561,45.8 \%$ male). 
There were 84,213,781 total billing records in the physician billing dataset from the unique individuals from within the dataset. The six cancers specifically examined were lung, prostate, breast, mesothelioma, colorectal and pancreatic cancer, representing in total 34,178 unique individuals.

Three cancers with high survival rates (breast, prostate, and colorectal) and three cancers with low survival rates (pancreatic, mesothelioma, and lung) were examined, using the health utilization data to differentially examine and compare trends in annual prevalence rates of these diagnoses over time in addition to the annual total cost of the specified cancers and their associated disorders (other disorders diagnosed for patients with a specific cancer) including odds ratios of the associated disorders given the presence of one of the specified cancers. We examined the annual rates of diagnosis for lung, breast, prostate, colorectal, pancreatic, and mesothelioma cancer using regional administrative health care billing data for the period of 1994-2009. We also compare rates of cancer diagnosis in youth, adult, and geriatric patients to examine the effects of aging and observe whether these rates are consistent across age groups. Patients were organized into three groups: youth $(<25$ years), adult ( 25 years -69 years), and geriatric ( $\geq 70$ years).

Based on the billing dataset, we recorded the number of unique individuals diagnosed with each cancer for each year from 1994-2009 in order to produce the annual prevalence rate of cancer diagnosis. This value was denominated by the total number of unique individuals receiving any physician diagnosis in the same annual period. Individuals may see their doctors in year one, year two and year three, hence the annual prevalence includes any new diagnoses which would account for the accumulation of prevalence from year to year. It is important to bear in mind that, once diagnosed with cancer, an individual could be counted in more than one year on the basis of survival and continuing to see a physician, whereas mortality and mobility (moving to the region) would constitute reduction of the future annual prevalence after an initial physician visit and diagnosis.

In this exploratory study, the annual prevalence rates of all cancer diagnoses were compared across three age groups. Patients under 25 years old were placed in the youth group. Patients of the age 25 to 69 were placed in the adult group. Patients 70 years and older were placed in the geriatric group.

Additionally, annual costs were tallied and represented in total by year and across years, as well as by average cost per patient over the 16 years study period.

Seventeen of the 18 broad categories of ICD-9 disorders (independent variable) classified on the basis of the physiological systems (e.g., blood and blood producing organs) or classes of disorders (e.g., parasites and infectious diseases) formed the independent variable used in the calculation of odds ratios. These categories did not include categories include $\mathrm{E}$ or $\mathrm{V}$ codes, which tend to function as a catchall consisting of a large number of heterogenous categories. The odds ratios were calculated for each of the broad ICD-9 categories based on the presence or absence of the six specified types of cancer (dependent variable). Ninety-five percent confidence intervals were calculated for each odds ratio. When the value one is included in the range of the $95 \%$ confidence intervals, there is no statistically significant relationship between the dependent and independent variables. Where the confidence intervals are below the value of one, the dependent variable has reduced odds of membership in the affirmative category of the independent variable. Where the confidence intervals are above the value of one, the dependent variable has increased the odds of membership in the affirmative category of the independent variable. Odds ratios for breast and prostate cancers were calculated on the basis of sex. All data was descriptive and represented in tabular form.

\section{Results}

The sample consisted of 261,896 unique individuals (96,347 male) with 452,069 physician billings for any cancer diagnoses and 8,773,664 associated disorder diagnoses. The mean age of the cancer patient group was 50.6 (SD 20.5) years of age compared to those without cancer (mean 40.0; SD 22.4 years). 
Table 2. Annual rate of cancer diagnosis per 1,000 reported for three age groups: youth $(<25$ years), adult ( 25 years -69 years), and geriatric ( $\geq 70$ years) for the period of 1994-2009

\begin{tabular}{llll}
\hline Year & Youth & Adult & Geriatric \\
\hline 1994 & 26.2 & 85.1 & 131.5 \\
1995 & 30.8 & 103.3 & 160.8 \\
1996 & 33.6 & 109.2 & 164.1 \\
1997 & 35.0 & 112.4 & 171.8 \\
1998 & 36.7 & 111.5 & 171.9 \\
1999 & 38.9 & 117.8 & 183.5 \\
2000 & 39.5 & 119.6 & 190.3 \\
2001 & 39.6 & 120.7 & 194.2 \\
2002 & 40.8 & 120.3 & 198.1 \\
2003 & 40.5 & 118.0 & 197.3 \\
2004 & 44.1 & 116.5 & 202.0 \\
2005 & 50.6 & 121.3 & 213.2 \\
2006 & 52.5 & 123.1 & 217.7 \\
2007 & 55.4 & 123.8 & 218.9 \\
2008 & 60.2 & 126.9 & 220.6 \\
2009 & 68.9 & 134.4 & 219.2 \\
\hline
\end{tabular}

Table 3. Annual rate of cancer diagnosis per 100,000 reported for lung, prostate, breast, colorectal, mesothelioma, and pancreatic cancer for the period of 1994-2009

\begin{tabular}{lllllll}
\hline Year & Colorectal & Breast & Prostate & Lung & Pancreatic & Mesothelioma \\
\hline 1994 & 234.9 & 189.2 & 156.5 & 88.9 & 15.8 & 5.3 \\
1995 & 292.1 & 230.4 & 201.5 & 104.4 & 20.1 & 5.5 \\
1996 & 307.6 & 246.2 & 213.9 & 119.2 & 21.8 & 3.8 \\
1997 & 323.3 & 266.3 & 202.4 & 121.6 & 24.1 & 6.4 \\
1998 & 328.4 & 263.4 & 213.2 & 128.1 & 20.8 & 5.7 \\
1999 & 389.4 & 325.1 & 252.2 & 155.2 & 23.2 & 7 \\
2000 & 401.8 & 330.8 & 243.8 & 170.6 & 25 & 9.6 \\
2001 & 425.7 & 357.8 & 262.1 & 183.9 & 30.9 & 12 \\
2002 & 468.4 & 389.9 & 267.6 & 193 & 38 & 9.9 \\
2003 & 461.4 & 380 & 287.9 & 185.5 & 36.5 & 11.6 \\
2004 & 493.6 & 403.4 & 292.6 & 200.8 & 42.4 & 12.4 \\
2005 & 523.4 & 437.5 & 299.9 & 189.7 & 43.1 & 10.8 \\
2006 & 543.7 & 452.4 & 297.3 & 200.2 & 46.4 & 11.1 \\
2007 & 605.3 & 505.7 & 305.9 & 194.2 & 51.3 & 14.2 \\
2008 & 617.5 & 509.5 & 332.7 & 199.4 & 46.6 & 14.6 \\
2009 & 631.7 & 528.3 & 337.4 & 200.5 & 56.3 & 16.1 \\
\hline
\end{tabular}

Annual rates of any cancer diagnosis were found to have increased across all three age groups from 1994 to 2009 (see Table 2). Out of the three groups, the geriatric group displays the highest annual cancer rate consistently during the 16-year period, while the youth group displays the lowest cancer rates. All three groups experienced their highest peak in rates in 2009. During the study period the youth group showed the highest proportional increase (by a factor of 2.6) followed by the geriatric group (factor of 1.7) then the adult group (factor of 1.6). 
Table 4a. Direct costs of cancer diagnoses (CDN\$)

\begin{tabular}{lllllll}
\hline Direct Cancer Costs & Colorectal & Breast & Prostate & Lung & Pancreatic & Mesothelioma \\
\hline 1994 & 197,871 & 254,103 & 15,533 & 131,036 & 25,668 & 4,477 \\
1995 & 308,691 & 341,113 & 21,048 & 168,154 & 46,683 & 3,913 \\
1996 & 294,238 & 368,140 & 21,002 & 172,681 & 46,943 & 3,328 \\
1997 & 300,061 & 417,372 & 20,636 & 193,880 & 43,829 & 4,241 \\
1998 & 307,240 & 434,511 & 21,150 & 210,463 & 59,226 & 2,941 \\
1999 & 294,044 & 546,483 & 30,605 & 280,724 & 53,289 & 8,758 \\
2000 & 410,848 & 585,636 & 24,917 & 312,841 & 76,281 & 12,124 \\
2001 & 431,073 & 610,044 & 46,026 & 343,963 & 87,425 & 14,527 \\
2002 & 545,407 & 848,349 & 51,082 & 427,539 & 129,734 & 11,505 \\
2003 & 118,751 & 281,108 & 10,216 & 118,803 & 23,358 & 3,557 \\
2004 & 468,580 & 802,711 & 34,195 & 398,693 & 156,334 & 10,373 \\
2005 & 584,992 & $1,271,418$ & 50,660 & 519,868 & 208,236 & 15,387 \\
2006 & 683,268 & $1,246,795$ & 44,481 & 548,979 & 144,640 & 12,841 \\
2007 & 656,612 & $1,307,961$ & 47,119 & 541,271 & 199,292 & 15,659 \\
2008 & 744,678 & $1,195,910$ & 55,228 & 586,148 & 190,124 & 19,847 \\
2009 & 751,489 & $1,297,678$ & 84,886 & 586,768 & 220,216 & 24,356 \\
Total & $7,097,843$ & $11,809,332$ & 578,784 & $5,541,811$ & $1,711,278$ & 167,834 \\
Average Cost per patient & 982 & 1,146 & 87 & 732 & 928 & 300 \\
\hline
\end{tabular}

Table 4b. Costs of cancer-associated diagnoses (CDN\$)

\begin{tabular}{lllllll}
\hline Associated Diagnoses Costs & Colorectal & Breast & Prostate & Lung & Pancreatic & Mesothelioma \\
\hline 1994 & $2,198,317$ & $2,837,772$ & 479,368 & $2,536,872$ & 613,903 & 194,214 \\
1995 & $2,956,459$ & $3,826,748$ & 623,180 & $3,338,041$ & 858,111 & 233,569 \\
1996 & $3,141,435$ & $3,998,065$ & 624,654 & $3,488,952$ & 850,289 & 217,961 \\
1997 & $3,191,632$ & $4,090,012$ & 649,950 & $3,474,692$ & 853,720 & 251,588 \\
1998 & $3,404,418$ & $4,324,609$ & 700,383 & $3,803,740$ & 932,238 & 268,578 \\
1999 & $3,846,023$ & $4,625,238$ & 760,728 & $4,304,059$ & $1,058,976$ & 447,741 \\
2000 & $4,172,332$ & $4,786,679$ & 766,548 & $4,574,998$ & $1,033,195$ & 423,248 \\
2001 & $4,663,485$ & $5,422,169$ & 837,489 & $4,886,881$ & $1,214,496$ & 463,816 \\
2002 & $5,233,260$ & $6,353,427$ & 963,274 & $5,161,472$ & $1,518,059$ & 461,780 \\
2003 & $1,369,963$ & $1,684,854$ & 245,690 & $1,321,617$ & 331,535 & 117,142 \\
2004 & $4,307,452$ & $5,336,556$ & 791,142 & $4,001,631$ & $1,042,789$ & 362,953 \\
2005 & $6,005,328$ & $7,313,578$ & $1,017,839$ & $5,393,924$ & $1,541,549$ & 490,139 \\
2006 & $6,518,175$ & $8,153,696$ & $1,044,777$ & $5,544,723$ & $1,474,613$ & 530,941 \\
2007 & $6,875,701$ & $8,488,320$ & $1,061,125$ & $5,477,052$ & $1,852,143$ & 603,615 \\
2008 & $7,168,310$ & $8,793,433$ & $1,114,712$ & $5,302,395$ & $1,608,289$ & 630,119 \\
2009 & $6,807,215$ & $8,874,670$ & $1,141,609$ & $4,929,768$ & $1,456,091$ & 789,607 \\
Total & $71,859,505$ & $88,909,826$ & $12,822,468$ & $67,540,817$ & $18,239,996$ & $6,487,011$ \\
Grand Total & $78,957,348$ & $100,719,158$ & $13,401,252$ & $73,082,628$ & $19,951,274$ & $6,654,845$ \\
Average Cost per patient & 9,943 & 8,629 & 1,922 & 8,922 & 9,892 & 11,584 \\
Total Patients & 7,227 & 10,304 & 6,673 & 7,570 & 1,844 & 560 \\
\hline
\end{tabular}

Annual rates of cancer diagnosis were found to have increased for all six types of cancers from 1994 to 2009 (see Table 3). All six cancers have increased over 16 years; colorectal cancer consistently yields the highest annual cancer rate in this group while mesothelioma cancer consistently yields the lowest. The six cancers at least doubled in annual cancer rates 
during this period; pancreatic cancer showed the highest proportional increase (15.8 per 100,000 to 56.3 per 100,000), while prostate cancer showed the lowest proportional increase (156.6 per 100,000 to 337.4 per 100,000). The three cancers with the highest proportional increase were pancreatic, mesothelioma, and breast (increased by factors of 3.6, 3.0, and 2.8 respectively). The three cancers with the lowest proportional increase were prostate, lung, and colorectal (increased by factors of 2.1, 2.3, and 2.7 respectively). Annual pancreatic cancer rates have almost quadrupled since 1994, while annual mesothelioma cancer rates have tripled since 1994. Out of the six cancers, pancreatic and mesothelioma cancer have the largest increase in annual cancer rate in the 16 years period examined.

Table 5. Odds ratio representing associated disease condition given a specific type of cancer diagnosis

\begin{tabular}{|c|c|c|c|c|c|c|c|}
\hline \multirow{2}{*}{$\begin{array}{l}\text { ICD Diagnosis Range } \\
\text { Categories }\end{array}$} & \multicolumn{7}{|c|}{ Odds Ratio [95\% confidence interval] } \\
\hline & $\begin{array}{l}\text { All Other } \\
\text { Neoplasms }\end{array}$ & Colorectal & Breast & Prostate & Lung & Pancreatic & $\begin{array}{l}\text { Mesothe- } \\
\text { lioma }\end{array}$ \\
\hline $\begin{array}{l}\text { 280-289: diseases of the } \\
\text { blood and blood-forming } \\
\text { organs }\end{array}$ & $\begin{array}{l}2.2 \\
{[2.17,2.23]}\end{array}$ & $\begin{array}{l}2.95 \\
{[2.82,3.08]}\end{array}$ & $\begin{array}{l}1.53 \\
{[1.47,1.6]}\end{array}$ & $\begin{array}{l}3.7 \\
{[3.52,3.89]}\end{array}$ & $\begin{array}{l}2.11 \\
{[2.02,2.22]}\end{array}$ & $\begin{array}{l}2.31 \\
{[2.1,2.53]}\end{array}$ & $\begin{array}{l}2.22 \\
{[1.88,2.63]}\end{array}$ \\
\hline 140-239: neoplasms & $\mathrm{n} / \mathrm{a}$ & $\begin{array}{l}2.45 \\
{[2.37,2.54]}\end{array}$ & $\begin{array}{l}2.16 \\
{[2.1,2.23]}\end{array}$ & $\begin{array}{l}2.83 \\
{[2.73,2.94]}\end{array}$ & $\begin{array}{l}2.34 \\
{[2.26,2.42]}\end{array}$ & $\begin{array}{l}2.46 \\
{[2.3,2.63]}\end{array}$ & $\begin{array}{l}2.7 \\
{[2.39,3.04]}\end{array}$ \\
\hline $\begin{array}{l}\text { 390-459: diseases of the } \\
\text { circulatory system }\end{array}$ & $\begin{array}{l}2.03 \\
{[2.02,2.05]}\end{array}$ & $\begin{array}{l}2.14 \\
{[2.07,2.22]}\end{array}$ & $\begin{array}{l}1.78 \\
{[1.73,1.84]}\end{array}$ & $\begin{array}{l}2.51 \\
{[2.42,2.6]}\end{array}$ & $\begin{array}{l}2.06 \\
{[1.99,2.13]}\end{array}$ & $\begin{array}{l}2.09 \\
{[1.96,2.24]}\end{array}$ & $\begin{array}{l}2.03 \\
{[1.8,2.3]}\end{array}$ \\
\hline $\begin{array}{l}\text { 240-279: endocrine, } \\
\text { nutritional and metabolic } \\
\text { diseases, and immunity } \\
\text { disorders }\end{array}$ & $\begin{array}{l}1.85 \\
{[1.84,1.87]}\end{array}$ & $\begin{array}{l}1.89 \\
{[1.82,1.96]}\end{array}$ & $\begin{array}{l}1.58 \\
{[1.53,1.63]}\end{array}$ & $\begin{array}{l}2.2 \\
{[2.11,2.28]}\end{array}$ & $\begin{array}{l}1.69 \\
{[1.63,1.75]}\end{array}$ & $\begin{array}{l}1.93 \\
{[1.8,2.07]}\end{array}$ & $\begin{array}{l}1.69 \\
{[1.48,1.93]}\end{array}$ \\
\hline $\begin{array}{l}\text { 520-579: diseases of the } \\
\text { digestive system }\end{array}$ & $\begin{array}{l}1.51 \\
{[1.5,1.52]}\end{array}$ & $\begin{array}{l}1.8 \\
{[1.74,1.86]}\end{array}$ & $\begin{array}{l}1.31 \\
{[1.27,1.35]}\end{array}$ & $\begin{array}{l}1.62 \\
{[1.56,1.68]}\end{array}$ & $\begin{array}{l}1.42 \\
{[1.37,1.47]}\end{array}$ & $\begin{array}{l}1.82 \\
{[1.71,1.95]}\end{array}$ & $\begin{array}{l}1.5 \\
{[1.32,1.7]}\end{array}$ \\
\hline $\begin{array}{l}320-359 \text { : diseases of the } \\
\text { nervous system }\end{array}$ & $\begin{array}{l}1.87 \\
{[1.85,1.89]}\end{array}$ & $\begin{array}{l}1.5 \\
{[1.43,1.57]}\end{array}$ & $\begin{array}{l}1.43 \\
{[1.37,1.48]}\end{array}$ & {$[1.92,2.12]$} & {$[1.41,1.55]$} & {$[1.3,1.57]$} & $\begin{array}{l}1.63 \\
{[1.39,1.92]}\end{array}$ \\
\hline 290-319: mental disorders & $\begin{array}{l}1.45 \\
{[1.43,1.46]}\end{array}$ & {$[1.29,1.38]$} & $\begin{array}{l}1.28 \\
{[1.24,1.32]}\end{array}$ & {$[1.5,1.62]$} & $\begin{array}{l}1.29 \\
{[1.25,1.34]}\end{array}$ & $\begin{array}{l}1.31 \\
{[1.22,1.4]}\end{array}$ & $\begin{array}{l}1.34 \\
{[1.19,1.52]}\end{array}$ \\
\hline $\begin{array}{l}\text { 580-629: diseases of the } \\
\text { genitourinary system }\end{array}$ & $\begin{array}{l}1.54 \\
{[1.53,1.55]}\end{array}$ & $\begin{array}{l}1.29 \\
{[1.24,1.33]}\end{array}$ & {$[1.16,1.23]$} & $\begin{array}{l}2.79 \\
{[2.69,2.89]}\end{array}$ & $\begin{array}{l}1.13 \\
{[1.09,1.17]}\end{array}$ & $\begin{array}{l}1.2 \\
{[1.12,1.29]}\end{array}$ & $\begin{array}{l}1.16 \\
{[1.02,1.32]}\end{array}$ \\
\hline $\begin{array}{l}710-739 \text { : diseases of the } \\
\text { musculoskeletal system and } \\
\text { connective tissue }\end{array}$ & $\begin{array}{l}1.35 \\
{[1.34,1.36]}\end{array}$ & $\begin{array}{l}1.22 \\
{[1.18,1.26]}\end{array}$ & $\begin{array}{l}1.21 \\
{[1.18,1.25]}\end{array}$ & $\begin{array}{l}1.32 \\
{[1.27,1.37]}\end{array}$ & $\begin{array}{l}1.19 \\
{[1.15,1.23]}\end{array}$ & $\begin{array}{l}1.17 \\
{[1.09,1.25]}\end{array}$ & $\begin{array}{l}1.2 \\
{[1.07,1.36]}\end{array}$ \\
\hline $\begin{array}{l}\text { 740-759: congenital } \\
\text { anomalies }\end{array}$ & $\begin{array}{l}1.92 \\
{[1.88,1.95]}\end{array}$ & $\begin{array}{l}1.2 \\
{[1.09,1.31]}\end{array}$ & $\begin{array}{l}1.18 \\
{[1.1,1.28]}\end{array}$ & $\begin{array}{l}1.14 \\
{[1.03,1.26]}\end{array}$ & $\begin{array}{l}0.96 \\
{[0.87,1.06]}\end{array}$ & $\begin{array}{l}1.01 \\
{[0.84,1.23]}\end{array}$ & $\begin{array}{l}1.21 \\
{[0.88,1.67]}\end{array}$ \\
\hline $\begin{array}{l}\text { 360-389: diseases of the } \\
\text { sense organs }\end{array}$ & $\begin{array}{l}1.27 \\
{[1.26,1.28]}\end{array}$ & $\begin{array}{l}1.19 \\
{[1.15,1.23]}\end{array}$ & $\begin{array}{l}1.16 \\
{[1.12,1.19]}\end{array}$ & $\begin{array}{l}1.31 \\
{[1.27,1.36]}\end{array}$ & $\begin{array}{l}1.11 \\
{[1.07,1.15]}\end{array}$ & $\begin{array}{l}1.13 \\
{[1.06,1.21]}\end{array}$ & {$[1,1.28]$} \\
\hline $\begin{array}{l}\text { 680-709: diseases of the } \\
\text { skin and subcutaneous } \\
\text { tissue }\end{array}$ & $\begin{array}{l}1.33 \\
{[1.32,1.34]}\end{array}$ & $\begin{array}{l}1.14 \\
{[1.1,1.18]}\end{array}$ & $\begin{array}{l}1.15 \\
{[1.12,1.19]}\end{array}$ & $\begin{array}{l}1.24 \\
{[1.19,1.28]}\end{array}$ & $\begin{array}{l}1.06 \\
{[1.03,1.1]}\end{array}$ & $\begin{array}{l}1.09 \\
{[1.02,1.17]}\end{array}$ & $\begin{array}{l}1.08 \\
{[0.95,1.23]}\end{array}$ \\
\hline $\begin{array}{l}\text { 780-799: symptoms, signs, } \\
\text { and ill-defined conditions }\end{array}$ & $\begin{array}{l}1.13 \\
{[1.12,1.14]}\end{array}$ & $\begin{array}{l}1.1 \\
{[1.06,1.14]}\end{array}$ & $\begin{array}{l}1.07 \\
{[1.04,1.1]}\end{array}$ & $\begin{array}{l}1.14 \\
{[1.1,1.18]}\end{array}$ & $\begin{array}{l}1.09 \\
{[1.06,1.13]}\end{array}$ & $\begin{array}{l}1.1 \\
{[1.03,1.17]}\end{array}$ & $\begin{array}{l}1.09 \\
{[0.97,1.23]}\end{array}$ \\
\hline $\begin{array}{l}\text { 001-139: infectious and } \\
\text { parasitic diseases }\end{array}$ & {$[1.23,1.25]$} & {$[1.05,1.13]$} & $\begin{array}{l}1.02 \\
{[0.98,1.05]}\end{array}$ & {$[1.02,1.11]$} & {$[0.9,0.97]$} & {$[0.97,1.13]$} & $\begin{array}{l}1.07 \\
{[0.93,1.22]}\end{array}$ \\
\hline $\begin{array}{l}\text { 800-999: injury and } \\
\text { poisoning }\end{array}$ & $\begin{array}{l}1.13 \\
{[1.12,1.14]}\end{array}$ & {$[1.05,1.13]$} & {$[1.13,1.21]$} & {$[1.04,1.13]$} & {$[0.99,1.07]$} & $\begin{array}{l}1.02 \\
{[0.95,1.1]}\end{array}$ & $\begin{array}{l}1.09 \\
{[0.96,1.24]}\end{array}$ \\
\hline $\begin{array}{l}460-519: \text { diseases of the } \\
\text { respiratory system }\end{array}$ & $\begin{array}{l}1.12 \\
{[1.11,1.13]}\end{array}$ & $\begin{array}{l}1.03 \\
{[0.99,1.06]}\end{array}$ & $\begin{array}{l}1.04 \\
{[1.01,1.07]}\end{array}$ & $\begin{array}{l}1.06 \\
{[1.02,1.1]}\end{array}$ & $\begin{array}{l}1.11 \\
{[1.07,1.15]}\end{array}$ & $\begin{array}{l}0.98 \\
{[0.91,1.04]}\end{array}$ & $\begin{array}{l}1.15 \\
{[1.02,1.3]}\end{array}$ \\
\hline $\begin{array}{l}760-779 \text { : certain conditions } \\
\text { originating in the perinatal } \\
\text { period }\end{array}$ & $\begin{array}{l}1.04 \\
{[1.02,1.06]}\end{array}$ & $\begin{array}{l}0.78 \\
{[0.69,0.87]}\end{array}$ & $\begin{array}{l}0.66 \\
{[0.6,0.72]}\end{array}$ & $\begin{array}{l}0.67 \\
{[0.57,0.78]}\end{array}$ & $\begin{array}{l}0.62 \\
{[0.55,0.7]}\end{array}$ & $\begin{array}{l}0.97 \\
{[0.8,1.19]}\end{array}$ & $\begin{array}{l}0.73 \\
{[0.48,1.11]}\end{array}$ \\
\hline $\begin{array}{l}\text { 630-679: complications of } \\
\text { pregnancy, childbirth, and } \\
\text { the puerperium }\end{array}$ & $\begin{array}{l}1.34 \\
{[1.32,1.35]}\end{array}$ & $\begin{array}{l}0.49 \\
{[0.45,0.54]}\end{array}$ & $\begin{array}{l}0.59 \\
{[0.56,0.62]}\end{array}$ & $\begin{array}{l}1.83 \\
{[1.58,2.13]}\end{array}$ & $\begin{array}{l}0.35 \\
{[0.32,0.39]}\end{array}$ & $\begin{array}{l}0.37 \\
{[0.3,0.45]}\end{array}$ & $\begin{array}{l}0.53 \\
{[0.39,0.71]}\end{array}$ \\
\hline
\end{tabular}

Note. The odds ratio for neoplasms does not include the dependent category. 
The six cancers maintain the same hierarchy of annual cancer rates throughout the 16 -year period. The cancer with the highest annual rate was consistently colorectal, followed by breast, prostate, lung, pancreatic, then mesothelioma cancer. All cancers experienced their highest peak in 2009 except for lung cancer, which had a peak rate of 200.8 per 100,000 in 2004 (see Table 3).

The upper section of Table 4 shows the direct costs of each type of cancer and the lower section shows the costs by cancer type of the associated broad ICD-9 categories of diagnosis. Each section is totalled and both sections are summed in the third last row from the bottom of the table. The last row of Table $4 \mathrm{a}$ and the second last row Table $4 \mathrm{~b}$ show the average cost per unique individual of direct cancer costs and associated category costs, respectively. The highest average cancer diagnosis cost per patient was for breast cancer, and the lowest was for prostate cancer. The highest average per patient associated diagnosis cost was for mesothelioma and the lowest was for prostate cancer. Breast cancer had the greatest overall total cost.

Table 5 shows the odds ratios based on each associated broad category of disorder (independent variable) given the presence of a specific type of cancer (dependent variable). The table is organized by the descending value of odds ratio within colorectal cancer. In the case of each dependent variable, the highest odds ratios were for blood and blood-forming organ disorders, other neoplasms, circulatory system disorders, endocrine, nutritional, metabolic and immunity disorders. The lowest odds ratios were for disorders related to complications of pregnancy childbirth and perinatal conditions.

\section{Interpretation}

Analysis of health utilization data has shown that the annual rate of diagnosis for lung, pancreatic, mesothelioma, prostate, breast, and colorectal have at least doubled from 1994 to 2009, with two of the cancers with the lowest survival rates (mesothelioma and pancreatic cancer) having the highest proportional increase among the six cancers (see Table 3). Consistent increase in annual rate of diagnosis may be related to the increased prevalence of risk factors for each cancer and perhaps equally an increase in the ability of physicians to diagnose these cancers. Other potential factors are discussed in the limitations section. Nevertheless, these increases within the specific types of cancers and increases noted by age are worthy of identification and concern. Furthermore, the annual rate of colorectal cancer appeared to be higher than either breast or prostate cancer. This was an unexpected finding compared to the literature and may represent the presence of a robust screening program for colorectal cancer in the Calgary zone.

Direct exposure to asbestos is a known risk factor for mesothelioma ${ }^{[8,10,11]}$. Asbestos was commonly used from the $1940 \mathrm{~s}$ to 1970 s in Canada ${ }^{[8]}$; the long latency period of 15 years -40 years for mesothelioma beginning from that period may explain rising numbers of mesothelioma diagnoses. Mesothelioma made up 30\% of occupational disease fatalities in Alberta in 2006 with the percentage steadily rising to $36 \%$ in $2011^{[12-17]}$. This raises concerns with the fact that the production, use, and export of asbestos are not currently banned in Canada.

Diabetes is a known risk factor for pancreatic cancer ${ }^{[18-22]}$ and between 1995 and 2007 the prevalence and incidence of diabetes in Alberta has more than doubled with the highest incidence rate in the Calgary area, peaking in the 55-65 years old age group ${ }^{[21]}$. This steady increase in both prevalence and incidence implicates diabetes in the increasing number pancreatic cancer diagnoses and as a major factor in increased annual rate of diagnosis of pancreatic cancer. Similarly obesity ${ }^{[24}$ is a recognized risk factor for both colorectal and pancreatic cancer and in Alberta colorectal cancer has the highest costs (\$31.6 million) attributable to obesity among 14 cancer sites ${ }^{[25]}$.

Age is also an important risk factor for many of the cancers examined; from 1996 to 2009 the 50-59 years old age group was estimated to more than double making it the fastest growing age group in Calgary with the 60-69 years old age group second fastest ${ }^{[26]}$. The median age in Alberta has increased from 31.3 years in 1991 to 36.5 years in $2011^{\text {[27] }}$. The growth 
of these age groups means that a higher percentage of Calgary's population is at risk for the more common cancers ${ }^{[28]}$ as risk increases after age $50^{[2]}$.

The Canadian Cancer Society speculated in 2007 that increased incidence of breast cancer is partly attributed to improved diagnostic technology and increased participation in screening programs. Participation in the Alberta Breast Cancer Screening Program (ABCSP) peaked in 2000 but has begun to plateau ${ }^{[29-31]}$. However annual rate of diagnosis has been steadily increasing since 1994 (see Table 3); as participation begins to plateau the rate of diagnosis continues to increase, suggesting that recent increases in rate of diagnosis are independent of participation.

Quality of screening can be measured by positive predictive value (PPV), which indicates the proportion of patients with an abnormal screen subsequently diagnosed with cancer. Since 1997 the PPV of ABCSP has been steadily increasing above the Canadian target of $\geq 6 \%$ PPV ${ }^{[29-31]}$. As screening quality increases previously undetected tumors may be diagnosed, therefore contributing to increased rates of diagnosis. There are no standard screening procedures or diagnostic tests in place in Canada for mesothelioma or pancreatic cancer and diagnosis relies on combination testing (e.g., computerized tomography scans, magnetic resonance imaging, and X-ray, etc. ${ }^{[32-34]}$ ). With no major breakthroughs in early stage screening diagnostic tools for mesothelioma or pancreatic cancer, screening tests are unlikely to be a major factor explaining the increasing rates of diagnosis.

Among all cancers examined, lung cancer exhibited a recent plateau in rate of diagnosis, which supports findings from the 2011 Canadian Cancer Statistics report. This may be related to decreasing trends in smoking tobacco among Canadians ${ }^{[35]}$; from 1966 to 2010 the proportion of Canadians 15 years or older that smoke has dropped from $45 \%$ to $17 \%{ }^{[36]}$. The 2011 Canadian Cancer Statistics report states that incidence and mortality has significantly declined since the mid-1980s for men, while for women they have both significantly increased since 1982 but have begun to plateau. The difference between trends lies in past differences in patterns of tobacco consumption; the drop in tobacco consumption for males preceded females by 20 years ${ }^{[4]}$.

In agreement with the 2009 Canadian Cancer Statistics report ${ }^{[37]}$, our results show that the youth group had the highest proportional increase (2.62) compared to the adult and geriatric groups (see Table 2). The rarity of cancers, reduced latency period, and aggressive development contribute to the inefficiency of cancer screening for youth, which may limit opportunities for primary prevention and be a factor contributing to increased rates of diagnosis in the youth group examined ${ }^{[38]}$.

The annual and overall costs of cancer treatment in the treatment of associated disorders provide a coherent framework on which to base planning for specific services related to the treatment of these types of cancers. Being able to allocate budget on the basis of both per capita and population density estimates is an advantage for any health service administration. Cost analysis represents one example of how health service utilization data may be of use for planning. Conjoined examination of health utilization costs associated with a range of cancers has not been examined in a large population. Fireman et al. (1997) did examine health utilization costs associated with cancers over 15 years in a stratified sample of less than 1,000 patients ${ }^{[40]}$ with values for breast $(\$ 35,000)$ and prostate $(\$ 29,000)$ cancers being most comparable to the present study. The present study average for breast $(\$ 8,629)$ and prostate $(\$ 1,922)$ cancers are lower than those reported by Fireman et al. ${ }^{[40]}$ and highlights the difficulty inherent in comparing study results across time. For example, Fireman study preceded this study by at least 13 years and therefore higher costs cannot be founded on the basis of inflation nor is cost reduction necessarily due to medical innovation and research.

In addition to costing data, the ability to use administrative data to calculate the odds ratios of having associated disorders within the broad groupings of ICD-9 disorders given the presence or absence of a type of cancer has advantages for health service administration. For example, planning may be based on understanding what specific diagnoses within the broad categories of ICD-9 diagnoses for which there are generally increased probability of membership given the presence of a specific cancer. The data presented in the present study is very compressed in terms of the broad grouping within large 
categories of diagnoses. The concept should be clear however that health service utilization data holds the potential to understand the following details related to the significant findings related to the increased likelihood of associated disorders: 1) Utilization data permits drilling down into the specific disorders related to specific types of cancer. 2) More sophisticated analysis algorithms may permit establishing whether or not certain clusters of the disorders within categories of associated disorder arise before or after the diagnosis of cancer. Developing an understanding of how cancers are associated with other disorders and how they arise in time are important next steps in our research agenda. The present findings point out the relevance of these relationships even within broad categories of ICD diagnoses.

In summary, health utilization data provides useful local information about the prevalence and costs of specific types of cancers that may generalize in the approach to planning comprehensive services for high-risk populations.

\section{Limitations}

The validity of the increasing rates of annual diagnosis may be questioned due to physician error in diagnosis. However, as all diagnoses are subject to the same error rate, thus the overall increase in rates of annual diagnosis is still valid. Individuals may have repeated diagnoses between years, yet the results represent annual cumulative prevalences that are increasing per capita rather at a steady state. The cause of the observed increase in prevalence over the period between the fiscal years 1994 and 2009 is not necessarily attributable to a true increase in the prevalence of the disease. Multiple factors may contribute to the observed increase. For example, better diagnostics, better education of physicians, better education of the public in respect to general public or media awareness, cancer-specific programs (e.g., mesothelioma), observation or reporting of symptoms, improved laboratory testing, screening sensitivity and specificity etc.

\section{Conclusions}

This study shows that the results from analyzing health utilization data reveal long term trends in rates of diagnosis. Overall, the long term prevalence rate of cancer based on physician billing appears substantially higher than that reported by the Canadian Cancer Society. By comparing annual rates of diagnosis to risk factor trends we can determine the impact of specific risk factors on development of disease as well as evaluating the efficacy of diagnostic tools. Long terms trends can project the future burden cancer patients will impose on the Albertan healthcare system and subsequently aid in planning strategies for cancer control as well as determine key areas to invest resources. These trends show that pancreatic cancer and mesothelioma, two rare cancers with high mortality rates, are growing at an alarming rate; we recommend further research into the causes behind this increase. While it is not possible to directly attribute differences in trends to specific variables, identification of associated variables, such as the existence of local screening programs as in the case of colorectal cancer, may in fact show trends in different communities between or within regions that can help to identify the salient causal factors associated with changes in prevalence over time.

The growing annual rate of diagnosis in Albertans under 25 years warrants further examination, in particular identifying which cancer types are contributing to the increasing rate, as well as evaluating current resources available to these patients.

Direct costs related to cancer diagnosis and associated diagnosis costs also are an important information source for understanding the differences between local and national trends. Comparing prevalence and costs of treatment along with survival rates, etc. may help to identify screening and treatment regimes that are more or less successful.

Identifying disorders associated with specific types of cancers will prove useful in regard to planning "true" clinical pathways for care (e.g., those experienced by the mass of patients). This level of complexity is not currently considered in such planning, which tends not to be data-driven, but rather being ad hoc and anecdotal. We have taken a first step towards describing disorders associated with different forms of cancer. Extending this work in future research through examining the time dependence in etiology of associated disorders will be particularly salient to health service planning and 
administration. In other words, it would be useful to know for planning purposes whether or not associated disorders tend to arise before, concurrently or after specific cancers. Furthermore, understanding the complex of disorders that arise within individual patients will ultimately have a direct influence on the types of treatments offered. The use of diagnostic profiles may in fact represent a salient component of contemporary metabolomics. The present paper is a small step in this direction.

\section{References}

[1] Statistics Canada. Leading causes of death in Canada. Government. Ottawa, ON: Government of Canada. 2008.

[2] Canadian Cancer Society's Steering Committee on Cancer Statistics. Canadian cancer statistics. Toronto, ON: Canadian Cancer Society. 2012.

[3] McDavid K, Lee J, Fulton JP, Tonita J, Thompson TD. Prostate cancer incidence and mortality rates and trends in the united states and canada. Public Health Rep. 2004; 119(2): 174. PMid: 15192905.

[4] Canadian Cancer Society's Steering Committee on Cancer Statistics. Canadian cancer statistics. Toronto, ON: Canadian Cancer Society. 2011.

[5] Cancer Care Ontario. Cancer fact: The most fatal cancers in ontario. Healthcare. Toronto, ON: Cancer Care Ontario. 2011.

[6] Siegel R, Naishadham D, Jemal A. Cancer statistics. CA: A Cancer Journal for Clinicians. 2012.

[7] Speer AG, Thursfield VJ, Torn-Broers Y, Jefford M. Pancreatic cancer: Surgical management and outcomes after 6 years of follow-up. Med J Aust. 2012; 196(8): 511-5. PMid: 22571308. http://dx.doi.org/10.5694/mja11.10890

[8] Marrett LD, Ellison LF, Dryer D. Canadian cancer statistics at a glance: Mesothelioma. Can Med Assoc J. 2008; $178(6): 677-8$. PMid: 18332380. http://dx.doi.org/10.1503/cmaj.080129

[9] Cree M, Lalji M, Jiang B, Carriere K, Beach J, Kamruzzaman A. Explaining alberta's rising mesothelioma rates. Chronic Dis Can. 2009; 29(4): 144-52. PMid: 19804678.

[10] Mesothelioma [Internet]; 2012; cited 8/21/2012. Available from: http://info.cancer.ca/cce-ecc/default.aspx?toc=27.

[11] Pass HI, Lott D, Lonardo F, Harbut M, Liu Z, Tang N, et al. Asbestos exposure, pleural mesothelioma, and serum osteopontin levels. N Engl J Med. 2005; 353(15): 1564-73. PMid: 16221779. http://dx.doi.org/10.1056/NEJMoa051185

[12] Occupational Health and Safety. Occupational disease fatalities accepted by the worker's compensation board. Government. Edmonton, AB: Government of Alberta Health Services; 2011.

[13] Occupational Health and Safety. Occupational disease fatalities accepted by worker's compensation board. Government. Edmonton, AB: Government of Alberta Health Services; 2010.

[14] Occupational Health and Safety. Occupational disease fatalities accepted by worker's compensation board. Government. Edmonton, AB: Government of Alberta Health Services; 2009.

[15] Occupational Health and Safety. Occupational disease fatalities accepted by worker's compensation board. Government. Edmonton, AB: Government of Alberta Health Services; 2008.

[16] Occupational Health and Safety. Occupational disease fatalities accepted by worker's compensation board. Government. Edmonton, AB: Government of Alberta Health Services; 2007.

[17] Occupational Health and Safety. Occupational disease fatalities accepted by worker's compensation board. Government. Edmonton, AB: Government of Alberta Health Services; 2006.

[18] Pancreatic [Internet]; 2012; cited 8/21/2012. Available from: http://info.cancer.ca.proxy.queensu.ca/cce-ecc/default.aspx?cceid=1228\&toc=36\&Lang=E.

[19] Everhart J, Wright D. Diabetes mellitus as a risk factor for pancreatic cancer. JAMA: the journal of the American Medical Association. 1995; 273(20): 1605-9. http://dx.doi.org/10.1001/jama.1995.03520440059037

[20] Lowenfels AB, Maisonneuve P. Epidemiology and prevention of pancreatic cancer. Jpn J Clin Oncol. 2004; 34(5): 238-44. http://dx.doi.org/10.1093/jjco/hyh045

[21] Johnson JA, Vermeulen S. Epidemiological trends of diabetes in alberta. Alberta Diabetes Atlas. 2007; 11-24.

[22] Ghadirian P, Baillargeon J, Simard A, Perret C. Food habits and pancreatic cancer: A case-control study of the francophone community in montreal, canada. Cancer Epidemiology Biomarkers \& Prevention. 1995; 4(8): 895-9. PMid: 8634663.

[23] Peng Y. Canadian consumer trends in obesity and food consumption. 2004.

[24] Colman R, Hayward K. The cost of obesity in alberta: Summary report. Healthcare. Calgary, AB: Alberta Health Services. 2010.

[25] Xiao F, Robson PJ, Ashbury FD, Hatcher J, Bryant HE. Smoking frequency, prevalence and trends, and their socio-demographic associations in alberta, canada. Canadian Journal of Public Health. 2010; 100(6): 453-8. 
[26] Statistics Canada. Table 051-0046 - estimates of population by census metropolitan area, sex and age group for july 1, based on the standard geographical classification (SGC) 2006, annual (persons). Government. Ottawa, ON: Government of Canada. 2006.

[27] Statistics Canada. Population by broad age groups and sex, counts, including median age, 1921 to 2011 for both sexes - alberta. Government. Ottawa, ON: Government of Alberta. 2012.

[28] Howlader N, Noone AM, Krapcho M, Neyman N, Aminou R, Altekruse SF, et al. SEER cancer statistics review, 1975-2009 (vintage 2009 populations). Health Research. Bethesda, MD: National Cancer Institute. 2012.

[29] Public Health Agency of Canada. Organized breast cancer screening programs in canada: Report on program performance in 2005 and 2006. Government. Ottawa, ON: Government of Canada. 2011.

[30] Health Canada. Organized breast cancer and screening programs: 1999 and 2000 report. Healthcare. Ottawa, ON: Government of Canada. 2003.

[31] Health Canada. Organized breast cancer and screening programs: 1997 and 1998 report. Healthcare. Ottawa, ON: Government of Canada. 2001.

[32] Alberta Provincial Thoracic Malignancies Tumour Team. Malignant pleural mesothelioma: Clinical practice guideline LU-009. Healthcare. Calgary, AB: Alberta Health Services. 2010.

[33] Miura F, Takada T, Amano H, Yoshida M, Furui S, Takeshita K. Diagnosis of pancreatic cancer. HPB. 2006; 8(5): 337-42. PMid: 18333085. http://dx.doi.org/10.1080/13651820500540949

[34] Pass HI, Carbone M. In: Current status of screening for malignant pleural mesothelioma. Seminars in thoracic and cardiovascular surgery; Elsevier. 2009; 97-104. PMid: 19822280.

[35] Stephens M, Siroonian J. Smoking prevalence: Implications of quitting. Health Reports. 1998; 9(4): 31-40. PMid: 9836878.

[36] Health Canada. Canadian tobacco use monitoring survey (CTUMS) 2010. Population Report. Ottawa, ON: Government of Canada. 2010.

[37] Canadian Cancer Society's Steering Committee. Canadian cancer statistics 2009. Health. Toronto, ON: Canadian Cancer Society. 2009.

[38] Cancer Care Ontario. Cancer care in young adults in Canada. Health. Toronto, Canada: Canadian Cancer Society. 2006.

[39] Canadian Cancer Society's Advisory Committee on Cancer Statistics. Canadian Cancer Statistics. Toronto, ON: Canadian Cancer Society. 2013.

[40] Fireman BH, Quesenberry CP, Somkin CP, Jacobson AS, Baer D, West D, et al. Kaiser Permanente Medical Care Program, Northern California Region, Oakland, USA. Health Care Financing Review. 1997; 18(4): 51-76. 